Fixed Point Theory, 23(2022), No. 1, 293-310

DOI: $10.24193 /$ fpt-ro.2022.1.19

http://www.math.ubbcluj.ro/ nodeacj/sfptcj.html

\title{
DECAY SOLUTIONS TO RETARDED FRACTIONAL EVOLUTION INCLUSIONS WITH SUPERLINEAR PERTURBATIONS
}

\author{
DO LAN* AND VU NAM PHONG** \\ * Department of Mathematics, Thuyloi University \\ E-mail: dolan@tlu.edu.vn \\ ** Department of Mathematics, Thuyloi University \\ E-mail: phongvn@tlu.edu.vn
}

\begin{abstract}
In this paper, we consider a class of abstract fractional differential inclusion with finite delay in which the multi-valued nonlinearity is possibly superlinear. We analyze some sufficient conditions that ensure the global solvability of problem. Our main result is the existence of a compact set of decay solutions to our problem by estimating the measure of noncompactness and using the fixed point theory for a condensing map. The obtained results will be applied to a concrete polytope fractional differential system.
\end{abstract}

Key Words and Phrases: Decay solutions, differential inclusion, fixed point, measure of noncompactness; MNC-estimate.

2020 Mathematics Subject Classification: 35B35, 47H08, 47H10.

\section{ACKNOWLEDGEMENT.}

This research is funded by the Vietnam National Foundation for Science and Technology Development (NAFOSTED) under grant number 101.02-2020.07. Vu Nam Phong is funded by Vingroup JSC and supported by the Master, PhD Scholarship Programme of Vingroup Innovation Foundation (VINIF), Institute of Big Data, code VINIF.2021.TS.149.

\section{REFERENCES}

[1] S. Adly, A. Hantoute, N.B. Tran, Lyapunov stability of differential inclusions involving proxregular sets via maximal monotone operators, J. Optim. Theory Appl., 182(2019), no. 3, 906934.

[2] M. Afanasova, Y-C. Liou, V. Obukhovskii, G. Petrosyan, On controllability for a system governed by a fractional-order semilinear functional differential inclusion in a Banach space, J. Nonlinear Convex Anal., 20(2019), no. 9, 1919-1935.

[3] N.T. Anh, T.D. Ke, Decay integral solutions for neutral fractional differential equations with infinite delays, Math. Methods Appl. Sci., 38(2015), no. 8, 1601-1622.

[4] W. Arendt, P. Banilan, Wiener regularity and heat semigroups on spaces of continuous functions, in: Topics in Nonlinear Analysis, Progress in Nonlinear Differential Equations Application, vol. 35 (Birkhauser, Basel, 1999), pp. 29-49. 
[5] E.G. Bazhlekova, Fractional Evolution Equations in Banach Spaces, Ph.D. Thesis, Eindhoven University of Technology, 2001.

[6] I. Benedetti, V. Obukhovskii, V. Taddei, Evolution fractional differential problems with impulses and nonlocal conditions, Discrete and Continuous Dynamical Systems - S, 13(2020), no. 7, 18991919.

[7] T. Blouhi, T. Caraballo, A. Ouahab, Topological method for coupled systems of impulsive stochastic semilinear differential inclusions with fractional Brownian motion, Fixed Point Theory, 20(2019), no. 1, 71-105.

[8] A. Haraux, M.A. Jendoubi, The Convergence Problem for Dissipative Autonomous Systems. Classical Methods and Recent Advances, Springer Cham Heidelberg New York Dordrecht London, 2015.

[9] N.V. Hung, V.M. Tam, D. O'Regan, Existence of solutions for a new class of fuzzy differential inclusions with resolvent operators in Banach spaces, Comput. Appl. Math., 39(2020), no. 2.

[10] M. Kamenskii, V. Obukhovskii, P. Zecca, Condensing Multivalued Maps and Semilinear Differential Inclusions in Banach Spaces, in: de Gruyter Series in Nonlinear Analysis and Applications, vol. 7, Walter de Gruyter, Berlin, New York, 2001.

[11] T.D. Ke, D. Lan, Global attractor for a class of functional differential inclusions with HilleYosida operators, Nonlinear Anal., 103(2014), 72-86.

[12] T.D. Ke, D. Lan, Decay integral solutions for a class of impulsive fractional differential equations in Banach spaces, Fractional Calculus and Applied Analysis, 17(2014), no. 1, 96-121.

[13] T.D. Ke, D. Lan, Fixed point approach for weakly asymptotic stability of fractional differential inclusions involving impulsive effects, J. Fixed Point Theory Appl., 19(2017), no. 4, 2185-2208.

[14] T.D. Ke, L.T.P. Thuy, Dissipativity and stability for semilinear anomalous diffusion equations with delay, Math. Meth. Appl. Sci., (2020), 1-17.

[15] A.A. Kilbas, H.M. Srivastava, J.J. Trujillo, Theory and Applications of Fractional Differential Equations, Elsevier, Amsterdam, 2006.

[16] A. Kristaly, I.I. Mezei, K. Szilak, Differential inclusions involving oscillatory terms, Nonlinear Anal., 197(2020), 111834.

[17] D. Lan, Decay solutions and decay rate for a class of retarded abstract semilinear fractional evolution inclusions, Taiwanese J. Math., 23(2019), no. 3, 625-651.

[18] E.N. Mahmudov, Optimal control of evolution differential inclusions with polynomial linear differential operators, Evol. Equ. Control Theory, 8(2019), no. 3, 603-619.

[19] J.S. Pang, D.E. Stewart, Differential variational inequalities, Math. Program., 113(2008), no. 2, 345-424.

[20] T. Sascha, Well-posedness for a general class of differential inclusions, J. Differential Equations, 268(2020), no. 11, 6489-6516.

[21] R.N. Wang, D.H. Chena, T.J. Xiao, Abstract fractional Cauchy problems with almost sectorial operators, J. Differential Equations, 252(2012), 202-235.

[22] J.R. Wang, A.M. Ibrahim, D. O'Regan, Global attracting solutions to Hilfer fractional differential inclusions of Sobolev type with noninstantaneous impulses and nonlocal conditions, Nonlinear Anal. Model. Control, 24(2019), no. 5, 775-803.

[23] J.R. Wang, X.Z. Li, W. Wei, On controllability for fractional differential inclusions in Banach spaces, Opuscula Math., 32(2012), 341-356.

[24] Y. Zhou, Basic Theory of Fractional Differential Equations, World Scientific, Singapore, 2014.

[25] Y. Zhou, F. Jiao, Existence of mild solutions for fractional neutral evolution equations, Comp. Math. Appl., 59(2010), 1063-1077.

Received: September 22, 2020; Accepted: January 14, 2021. 
